\title{
RESEARCH
}

Open Access

\section{TEVAR versus open repair of blunt traumatic descending aortic injury in polytraumatic patients involved in motor vehicle accidents}

Imthiaz Manoly ${ }^{1}$, Mohamed El Tahan², Maymoona Al Shuaibi², Fatimah Adel², Mohammed Al Harbi², Yasser Elghoneimy ${ }^{3}$ and Mohamed Abdel Hafez Fouly ${ }^{4^{*}}$ (1)

\begin{abstract}
Background: Thoracic endovascular aortic repair (TEVAR) is the standard-of-care for treating traumatic aortic injury (TAI). Few retrospective studies compared TEVAR to open repair in blunt traumatic aortic injury (BTAI). Our objectives were to compare the early outcomes of TEVAR for blunt traumatic descending aortic injury to open repair (OR) in polytraumatic patients involved in motor vehicle accidents (MVA).

Results: Between February 2005 and April 2017, 71 patients with TAl due to MVA presented to our institution. All patients with descending aortic injuries were considered for open repair $(n=41)$ or TEVAR $(n=30)$ if there was no contraindication. The primary outcome was mortality, and secondary outcomes were stroke, paraplegia, intensive care unit (ICU), and hospital stay.

The mean age was $28.4 \pm 10.1$ years in the OR group and $33.3 \pm 16.6$ years in TEVAR-group $(P=0.13)$. The injury severity scores were $41 \pm 10$ in the OR group and $33 \pm 17$ in the TEVAR group $(P=0.03)$. Patients in the OR group underwent emergency repair with a mean time of $0.56 \pm 0.18$ days from arrival. The TEVAR group had a longer time interval between arrival and procedure $(2.1 \pm 1.7$ days, $P=0.001)$. The OR group had more blood transfusion (24 (58.5\%) vs. $8(27.5 \%), P=0.002)$, renal impairment (6 (14.6\%) vs. 1 (5.50\%), $P=0.23)$, and wound infection (21 $(51.2 \%)$ vs. $3(10 \%), P<0.001)$. Three TEVAR patients had a perioperative stroke compared to two patients in the OR group $(P=0.64)$. There was no difference in the mean ICU ( $6 \pm 8.9$ vs. $5.3 \pm 2.9$ days; $P=0.1)$ or hospital stay $(20.1$ \pm 12.3 vs. $20.1 \pm 18.3, P=0.62$ ) between the two groups. There were four deaths in the OR group and none in the TEVAR group $(P=0.13)$.

Conclusion: The results of TEVAR were comparable with the open repair for traumatic aortic injury with good early postoperative outcomes. TEVAR repair could be associated with lower mortality, blood transfusion, and infective complications. However, the complexity of the injury and technical challenges were higher in the open group.
\end{abstract}

Keywords: TEVAR, Traumatic descending aortic injury, open repair

\footnotetext{
* Correspondence: mhafez1982.gf@gmail.com

${ }^{4}$ Cardiothoracic Surgery Department, Cairo University, Cairo, Egypt

Full list of author information is available at the end of the article
}

\section{Springer Open}

(c) The Author(s). 2021 Open Access This article is licensed under a Creative Commons Attribution 4.0 International License, which permits use, sharing, adaptation, distribution and reproduction in any medium or format, as long as you give appropriate credit to the original author(s) and the source, provide a link to the Creative Commons licence, and indicate if changes were made. The images or other third party material in this article are included in the article's Creative Commons licence, unless indicated otherwise in a credit line to the material. If material is not included in the article's Creative Commons licence and your intended use is not permitted by statutory regulation or exceeds the permitted use, you will need to obtain permission directly from the copyright holder. To view a copy of this licence, visit http://creativecommons.org/licenses/by/4.0/. 


\section{Background}

Traumatic aortic injury (TAI) is the second most common cause of death in trauma patients after head trauma $[1,2]$. The most common site for blunt traumatic aortic injury (BTAI) is the isthmus [3, 4]. Less than two decades ago, the reported incidence of TAI mortality was $30 \%$ due to its significant impact on multiple organs and lack of timely medical management [5]. With the advent of increased skillset and newer techniques, it has now been possible to intervene on such patients with better outcomes. However, the mortality and morbidity associated with open surgical repair are still high [4]. In a recent meta-analysis, thoracic endovascular aortic repair (TEVAR) was associated with better mortality and morbidity compared to surgical repair [6-8]. However, patients who undergo TEVAR are usually different from those who have open repair. Therefore, our objective was to compare patients' characteristics and early outcomes of TEVAR versus the open repair (OR) for the management of BTAI in polytraumatic patients after motor vehicle accidents.

\section{Methods}

We carried out a retrospective study on all trauma patients diagnosed with aortic injury due to motor vehicle accidents between February 2005 and April 2017 in a University Hospital. All patients aged above 16 years who had traumatic aortic injury were included in the study $(n=71)$. The exclusion criteria were limited to patients who did not have any aortic intervention because of frailty or not fit for any intervention. We grouped the patients according to the surgical technique into open repair $(n=41)$ and TEVAR $(n=30)$. The Institutional review board approved this study.

\section{Data collection}

We collected patients' demographics, operative, and postoperative data during the hospital stay and in the outpatient clinic. The primary outcome was in-hospital mortality, and the secondary outcomes were postoperative complications, length of intensive care unit (ICU), and hospital stay.

\section{Emergency department and preoperative management}

We followed a systematic and standardized approach in the emergency department for the management of polytraumatized patients. The primary survey included airway management, cervical spine stabilization, and optimizing breathing and circulation.

We monitored pulse oximetry, non-invasive blood pressure monitoring, core temperature, and urinary output. The patients had to be cleared of pelvic injury before insertion of a urinary catheter. Fluid resuscitation was implemented through two wide-bore peripheral cannulae with crystalloid fluids. In severe bleeding, the major hemorrhage pathway was activated, and packed red blood cells (or blood products) were infused appropriately. The emergency doctors performed ACLS and ATLS assessment and management to avoid delays in initiating immediate management. If the patient was stable, central venous lines were inserted under ultrasound guidance for fluid and blood pressure management.

All trauma patients were screened as per standardized imaging protocols, including portable X-rays, bedside fast ultrasound scan, and computed tomogram ( \pm angiogram). If there was any suspicion of pericardial effusion or tamponade, a transthoracic echocardiogram was performed ( \pm drainage).

The diagnosis of descending thoracic injury was made radiologically with CT aortography supplemented with transthoracic or transesophageal echocardiography. Traumatic aortic injuries were graded according to the Azizzadeh classification [9].

\section{Anesthetic management}

Anesthetic technique was standardized in all patients, and the doses of anesthetic medications varied according to the patients' hemodynamic response. For hemodynamically stable patients, intravenous propofol $(1-2.5 \mathrm{mg} / \mathrm{kg})$ in combination with fentanyl $(2-3 \mu \mathrm{g} / \mathrm{kg})$ or sufentanil $(0.2-0.3$ $\mu \mathrm{g} / \mathrm{kg}$ ) were administered. Etomidate $(0.2-0.3 \mathrm{mg} / \mathrm{kg})$ was also considered a good alternative in unstable patients due to a better cardiovascular profile.

Double lumen intubation and ventilation isolating the left lung was used for better visualization during surgical manipulations. The ventilation was maintained with a tidal volume of $6-8 \mathrm{ml} / \mathrm{kg}$ with or without positive endexpiratory pressure (PEEP) of $5 \mathrm{~cm} \mathrm{H}_{2} \mathrm{O}$, according to the anesthetist's preference. A single dose of 5000 IU of heparin was administered, and extracorporeal circulatory support was kept as a standard backup in all OR cases.

\section{Surgical treatment (open repair)}

A standard left posterolateral thoracotomy approach in the fourth intercostal space was used in all cases. The vascular clamps were applied beyond the left subclavian artery proximally and to the descending thoracic aorta beyond the site of injury distally. During aortic crossclamping, the hemodynamic stability was maintained with optimal anesthetic depth, vasoactive medications, and intravenous beta-blockers to prevent persistent tachycardia. The surgical repairs were performed through the clamp and sew techniques, including a direct end to end anastomosis, interposition graft repair, or patch repair using gel-impregnated woven Dacron prosthesis. We did not use a cell saver system for any patient during the study period. 


\section{Thoracic endovascular repair (TEVAR)}

TEVAR was performed in the interventional radiology suite with a cardiopulmonary bypass backup. A cardiac surgeon, an interventional radiologist, an anesthetist, and an experienced scrub nurse were present for all cases.

Under general anesthesia, a single dose of $5000 \mathrm{IU}$ intravenous heparin was administered; after the femoral cutdown, the common femoral artery was dissected to provide access to the descending thoracic aorta. Under the fluoroscopic guidance with a guidewire and angiographic catheter, an aortogram of the entire aorta was performed to identify the tear and confirm the landing zone.

The Valiant ${ }^{\mathrm{m}}$ thoracic aortic stent-graft (Medtronic, Parkway, Minneapolis, USA) was used. The diameter of the prosthesis required was measured from the CT and confirmed on the angiogram. The stents were slightly oversized to ensure a good seal. The stents were then deployed in the descending aorta under fluoroscopic guidance. An aortogram was performed to confirm satisfactory positioning of the stent and to rule out any endoleaks. After removing the device delivery system, the femoral incision site was closed horizontally with appropriate Vicryl sutures (Ethicon, Inc., Somerville, NJ, USA) to prevent any vessel lumen narrowing.

\section{Statistical analysis}

Qualitative data were compared with the chi-square test or Fisher exact test when appropriate and presented as numbers and percentages. Quantitative data were expressed as mean and standard deviation and compared with the t-test if normally distributed or Mann-Whitney test if non-normally distributed. SPSS v. 25 (IBM Corp, Armonk, NY, USA) was used to perform the statistical analysis, and a $p$ value of less than 0.05 was considered statistically significant.

\section{Results}

A total of 71 cases of TAI after MVA were identified during the study period. The OR group were all male drivers, while 3 of the 30 patients in the TEVAR group were females and passengers $(P=0.07)$. The mean age $( \pm \mathrm{SD})$ was $28.4 \pm 10.1$ years in the OR group and $33.3 \pm 16.6$ years in the TEVAR group. The mean injury severity score was significantly higher in the OR group (Table 1). In all the patients who survived, the site of aortic injury was close to the isthmus.

Thirty-six patients had procedures within $24 \mathrm{~h}$ of admission to the hospital. Five patients had an OR within 1-4 days after the incidents. After introducing TEVAR in 2013, all cases were attempted by TEVAR if there was no contraindication. Though TEVAR procedures were done within $24 \mathrm{~h}$ of admission to our hospital, there was a delay from 'door to procedure' due to technical and logistical issues. Time to surgery was significantly longer in the TEVAR group $(P<0.001)$ (Table 2$)$.

In the OR group, 33 cases were repaired by a direct end to end anastomosis after excising the injured aortic segment. Six patients had a bigger tear and had the aortic segment replaced with a gel-impregnated woven Dacron interposition graft. Two of them had a small tear and hence only had patch repair with Dacron graft. The mean $( \pm \mathrm{SD})$ aortic cross-clamp time was $35 \pm 8.71 \mathrm{~min}$. There was one on-table death due to uncontrollable bleeding. In the TEVAR group, 29 stents were successfully deployed in the first attempt, and 1 patient required re-deployment of the stent. There was no conversion to open repair.

In the OR group, no patient required distal shunt, left heart bypass, or reimplantation of intercostal arteries to maintain spinal cord perfusion. We did not use lumbar drainage of CSF due to the complexity of the polytrauma. We used near-infrared spectroscopy probes with detectors (INVOS SOMANETIC 5100, Troy, MI) in 12 patients on the back in the T10-L2 posterior flank.

There was a significant reduction in the procedure's mean duration $(2.2 \pm 0.90$ vs. $5 \pm 3.2 \mathrm{~h} ; P=0.04)$ in the TEVAR group. The OR group had more blood transfusion requirements $(24(58.5 \%)$ vs. $8(27.5 \%))$, renal impairment (6 (14.6\%) vs. $1(5.5 \%))$, and wound infection (21 (51.2\%) vs. $3(10.3 \%)$ ). (Table 2) Three TEVAR patients suffered a perioperative stroke compared to two patients in the OR group. There was no difference in the mean ICU or hospital stay between the two groups. There were four deaths in the OR group and none in the TEVAR group. Three patients died due to postoperative ARDS in the ICU, and three patients died from multiorgan failure.

\section{Discussion}

The outcomes of traumatic aortic injury improved after the introduction of TEVAR into clinical practice. We compare the outcomes of TEVAR to open repair in patients with blunt traumatic descending aortic injury. Patients who had open repair had a higher injury severity score, blood loss, transfusion, and infective complications. There was no difference between approaches in the postoperative complications and length of stay.

Multiple factors contributed to the poor prognosis of patients with traumatic descending aortic injury [10]. Along with the aorta affected by the high-speed collision, other major organs were commonly involved in more than two-thirds of similar incidents in the literature [11]. The other major organs' involvement was an independent risk factor for high mortality in these patients [12]. 
Table 1 Preoperative data

\begin{tabular}{|c|c|c|c|}
\hline Characteristic & Open repair $(N=41)$ & TEVAR $(N=30)$ & $P$ value \\
\hline \multicolumn{4}{|l|}{ Demographics } \\
\hline Age (mean $\pm S D$ ) years & $28.4 \pm 10.1$ & $33.3 \pm 16.6$ & 0.13 \\
\hline Gender (male) $n$ (\%) & $41(100)$ & $27(90)$ & 0.07 \\
\hline \multicolumn{4}{|l|}{ Comorbidities n (\%) } \\
\hline Diabetes n (\%) & $4(9.7)$ & $2(6.6)$ & $>0.99$ \\
\hline Hypertension $n(\%)$ & $4(9.7)$ & $3(10)$ & $>0.99$ \\
\hline Neurological status n (\%) & & & 0.002 \\
\hline Normal/intact & $6(14.6)$ & $16(53.3)$ & \\
\hline GCS-mild & $3(7.3)$ & $4(13.3)$ & \\
\hline GCS-moderate & $28(68.3)$ & $9(30)$ & \\
\hline GCS severe & $4(9.7)$ & $1(3.3)$ & \\
\hline Pulmonary disease $n(\%)$ & $2(4.8)$ & $0(0)$ & 0.51 \\
\hline Extracardiac arteriopathy $n(\%)$ & $3(7.3)$ & $0(0)$ & 0.26 \\
\hline \multicolumn{4}{|l|}{ Associated injuries n (\%) } \\
\hline Hemopneumothorax & $39(95.1)$ & $9(30)$ & 0.006 \\
\hline Lung contusion & $36(87.8)$ & $9(30)$ & 0.08 \\
\hline Rib fracture & $37(90.2)$ & $6(20)$ & $<0.001$ \\
\hline Hepatic injury & $4(9.7)$ & $5(16.6)$ & 0.48 \\
\hline Splenic injury & $3(7.3)$ & $9(30)$ & 0.02 \\
\hline Brain contusion/injury & $8(19.5)$ & $6(20)$ & $<0.99$ \\
\hline Maxillofacial injury & $3(7.3)$ & $2(6.6)$ & $<0.99$ \\
\hline Vertebral injury & $9(21.9)$ & $2(6.6)$ & 0.1 \\
\hline Fractures (major) & 0 & $12(40)$ & $<0.001$ \\
\hline Fractures (minor) & 0 & $11(36.6)$ & $<0.001$ \\
\hline Injury severity score (mean \pm SD) & $41 \pm 10$ & $33 \pm 17$ & 0.03 \\
\hline Preoperative critical status $n(\%)$ & $4(9.7)$ & $11(36.6)$ & 0.008 \\
\hline
\end{tabular}

GCS Glasgow coma score

Traditionally, open repairs were attempted in our institute with varied outcomes. The open repair involved a left postero-lateral thoracotomy with different types of clamp and sew techniques of the aortic wall either with or without cardiopulmonary bypass. The mortality associated with open repairs were reported to be approximately thirty percent in a few studies $[6,10,13]$. This ratio was consistent with the data from the National Adult Cardiac Surgical Database of The Society of Cardiothoracic Surgeons of Great Britain and Ireland, which reported an operative mortality of $28.6 \%$ [14]. Hence, TAI surgery is now reserved in our institute, as with most aortic centers, due to high mortality and morbidity. However, the mortalities recorded in earlier registries have not reported the aortic rupture's grade and cannot be directly correlated with the prognosis. In our experience, mortality was better than the reported literature; however, most of our cases were grade I and II of the BTAI Society of Vascular Surgery classification [15]. One of the observations we had in our limited experience was the delay in transferring polytrauma patients from local hospitals to our institute. This delay, combined with OR patients' longer operative time, did have a detrimental effect on such cohort prognosis. In this polytrauma setting, every effort was made to be less invasive and have effective time management. Initially, our door to procedure time with TEVAR was longer due to logistic reasons. With better coordination and staff management, our results improved, and every traumatic aortic case was considered for TEVAR unless contraindicated.

Although there are no randomized controlled trials to prove the efficacy of TEVAR over OR, it is now considered the standard of care to manage the traumatic descending aortic injury in the absence of any contraindications and with favorable anatomy [15-17]. Several groups have reported their experience with TEVAR with comparable outcomes to OR [18-20]. These studies demonstrated technical feasibility and low periprocedural complication rates. 
Table 2 Operative and postoperative data

\begin{tabular}{|c|c|c|c|}
\hline Characteristic & Open repair $(N=41)$ & TEVAR $(N=30)$ & $P$ value \\
\hline \multicolumn{4}{|l|}{ Operative data } \\
\hline Procedure urgency $n(\%)$ & & & 0.08 \\
\hline Scheduled & $5(12.1)$ & $9(30)$ & \\
\hline Urgent & $36(87.8)$ & $21(70)$ & \\
\hline Time to surgery (mean \pm SD) days & $0.56 \pm 0.18$ & $2.09 \pm 1.71$ & 0.001 \\
\hline Successful surgerylgraft deployment n (\%) & $40(97.5)$ & $29(96.55)$ & $>0.99$ \\
\hline Operative blood loss (> $500 \mathrm{ml}$ ) $n(\%)$ & $27(65.85)$ & $6(20)$ & $<0.001$ \\
\hline Intraoperative blood transfusion $n(\%)$ & $24(58.5)$ & $6(20))$ & 0.002 \\
\hline \multicolumn{4}{|l|}{ Postoperative data } \\
\hline Neurological complications n (\%) & $2(4.8)$ & $3(10)$ & 0.64 \\
\hline Renal complications $n(\%)$ & $6(14.6)$ & $1(3.3)$ & 0.23 \\
\hline Infective complications n (\%) & $21(51.2)$ & $3(10)$ & $<0.001$ \\
\hline Arrhythmias $n(\%)$ & 0 & $1(3.3)$ & $>0.99$ \\
\hline \multicolumn{4}{|l|}{ Length of stay } \\
\hline Intensive care unit, days (mean \pm SD) & $6 \pm 8.9$ & $5.26 \pm 2.9$ & 0.1 \\
\hline Postoperative stay, days (mean \pm SD) & $20.1 \pm 12.31$ & $20.05 \pm 18.25$ & 0.62 \\
\hline Mortality n (\%) & $4(9.7)$ & 0 & 0.13 \\
\hline
\end{tabular}

The scientific evidence comparing conventional OR and TEVAR for TAI $[7,17,21,22]$ are also limited by them being retrospective observational studies, as was the case with our research. We started our TEVAR program in 2013 and have now successfully performed more than 40 patients ever since. In our experience, the early outcome with TEVAR has been at least as good as that with OR. However, we had more cases of stroke with TEVAR though it was not statistically significant. We did not have any significant spinal cord injury in either group of our study to make a proper comparison between them.

The reporting of long-term durability of both open repair and endovascular stenting is very limited $[18,20$, 23]. In our study, we had intended to follow-up with our patients on an annual basis with a CT aortogram to ensure the stability of the thoracic stent and the integrity of the aortic vessel wall. However, since our cohort mainly comprised young male drivers from a wide geographical area, they could not return for regular followups or their surveillance computed tomography.

The main stages in our management for this cohort who had sustained a deceleration/acceleration injury with potential aortic injury were to rapidly stabilize the cardiopulmonary status, appropriate trauma imaging, identification of other associated injuries to prioritize early or delayed prompt open surgical versus endovascular repair, close hemodynamic and neurological monitoring, and prompt interventions and intensive postoperative care. All of these have improved prognosis and reduced the incidence of postoperative complications.

\section{Limitations}

As with previous studies in the literature, our study's main limitations are the small cohort, and the study was retrospective. However, it will be difficult to perform a randomized controlled trial as this is a highly morbid condition. Current practice guidelines of the Society of Vascular Surgery for Traumatic Aortic Injury have been framed and updated based on observational studies [15]. Lack of long-term endovascular stenting outcomes is a shortcoming of this study that could not provide local and national recommendations for TEVAR in all BTAI.

\section{Conclusion}

The results of TEVAR are comparable with the open repair for traumatic aortic injury with good early postoperative outcomes. TEVAR repair could be associated with lower mortality, blood transfusion, and wound infection. However, the complexity of the injury and technical challenges were higher in the open group.

\section{Abbreviations \\ TEVAR: Thoracic endovascular aortic repair; TAl: Traumatic aortic injury; MVA: Motor vehicle accidents; OR: Open repair; ICU: Intensive care unit; ISS: The injury severity scores; ACLS: Advanced cardiac life support; ATLS: Advanced trauma life support; CT: Computed tomographs; SD: Standard deviation \\ Acknowledgements \\ Presented as an abstract at the Society of Cardiac and Thoracic Surgery (SCTS) Annual Meeting 2019 (10-12th March 2019)-London. None.}

\section{Authors' contributions}

$I M, A M T$, and L MS analyzed and interpreted the patient data regarding the TEVAR procedures that was done. FA and $\mathrm{N} \mathrm{MH}$ are responsible of drafting the work and revising it critically for important intellectual content. YG and 
MF are responsible for operating the cases and final supervision for the academic work done by the whole team. Finally, all authors read and approve the final manuscript.

\section{Funding}

None

\section{Availability of data and materials}

Available upon request.

\section{Ethics approval and consent to participate}

Ethical approval is from the ethics committee of King Fahd Hospital of the University Alkhobar in the 8th departmental meeting of surgery department and committee reference number is 2341

For ethics approval, it is available upon request and for consent to participate not applicable as it is retrospective study

\section{Consent for publication}

Not applicable as it is a retrospective study.

\section{Competing interests}

The authors declare that they have no competing interests.

\section{Author details}

${ }^{1}$ Cardiology Center, King Fahd Hospital of the University, Dammam, Kingdom of Saudi Arabia. ${ }^{2}$ King Fahd Hospital of the University, Dammam, Kingdom of Saudi Arabia. ${ }^{3}$ General Surgery Department, King Fahd Hospital of the University, Dammam, Kingdom of Saudi Arabia. ${ }^{4}$ Cardiothoracic Surgery Department, Cairo University, Cairo, Egypt.

Received: 1 December 2020 Accepted: 28 January 2021

Published online: 22 February 2021

\section{References}

1. Clancy TV, Gary Maxwell J, Covington DL, Brinker CC, Blackman D (2001) A statewide analysis of level $\mathrm{i}$ and ii trauma centers for patients with major injuries. J Trauma. 51(2):346-51.

2. Buz S, Zipfel B, Mulahasanovic S, Pasic M, Weng Y, HetzerR (2008) Conventional surgical repair and endovascular treatment of acute traumatic aortic rupture. Eur J Cardiothorac Surg. 34(3):700-10.

3. Richens D, Field M, Neale M, Oakley C (2002) The mechanism of injury in blunt traumatic rupture of the aorta. Eur J CardiothoracSurg. 21(2):288-93.

4. Schmoker JD et al (2008) A novel model of blunt thoracic aortic injury: a mechanism confirmed? J Trauma - Inj Infect Crit Care. 46(5):920-27.

5. Butler KL, Moore EE, Harken AH (1996) Traumatic rupture of the descending thoracic aorta. AORN J. 63(5):917-25.

6. Jonker FHW, Giacovelli JK, Muhs BE, Sosa JA, Indes JE (2010) Trends and outcomes of endovascular and open treatment for traumatic thoracic aortic injury. J Vasc Surg. 61(6):681-96.

7. Xenos ES, Bietz GJ, Davenport DL (2011) Endoluminal versus open repair of descending thoracic aortic rupture: a review of the national trauma databank. Ther Adv Cardiovasc Dis. 5(5):221-25

8. Tang GL et al (2008) Reduced mortality, paraplegia, and stroke with stent graft repair of blunt aortic transections: a modern meta-analysis. J Vasc Surg. 47(3):671-75.

9. Azizzadeh A et al (2013) An outcome analysis of endovascular versus open repair of blunt traumatic aortic injuries. J Vasc Surg. 57(1):108-15.

10. Cowley RA, Turney SZ, Hankins JR, Rodriguez A, Attar S, Shankar BS (1990) Rupture of thoracic aorta caused by blunt trauma: a fifteen-year experience. In: Journal of thoracic and cardiovascular surgery

11. Riesenman PJ, Brooks JD, Farber MA (2012) Acute blunt traumatic injury to the descending thoracic aorta. J Vasc Surg. 56(5):1274-80.

12. Kwolek CJ, Blazick E (2010) Current management of traumatic thoracic aortic injury. Semin Vasc Surg. 23(4):215-20.

13. von Oppell UO, Dunne T, De Groot KM, Zilla P (1994) Spinal cord protection in the absence of collateral circulation: meta-analysis of mortality and paraplegia. J Card Surg. 266(3):294-305.

14. Akowuah E, Baumbach A, Wilde P, Angelini G, Bryan AJ (2007) Emergency repair of traumatic aortic rupture: endovascular versus conventional open repair. J Thorac Cardiovasc Surg. 134(4):897-901.
15. Lee WA et al (2011) Endovascular repair of traumatic thoracic aortic injury: clinical practice guidelines of the Society for Vascular Surgery. J Vasc Surg. 53(1):187-92.

16. Hellgren T et al (2019) Outcome of thoracic endovascular aortic repair in 8 countries - report from an international registry collaboration. Eur J Vasc Endovasc Surg. 58(6):578-95.

17. Hoffer EK, Forauer AR, Silas AM, Gemery JM (2008) Endovascular stent-graft or open surgical repair for blunt thoracic aortic trauma: systematic review. J Vasc Interv Radiol. 19(8):1153-64.

18. Canaud L, Marty-Ané C, Ziza V, Branchereau P, Alric P (2015) Minimum 10year follow-up of endovascular repair for acute traumatic transection of the thoracic aorta. J Thorac Cardiovasc Surg. 142(5):1032-37.

19. Serra R et al (2015) Endovascular repair for acute traumatic transection of the descending thoracic aorta: experience of a single Centre with a 12-years follow up. J Cardiothorac Surg. 10:171.

20. Szostek $M$ et al (2016) Endovascular treatment of traumatic rupture of thoracic aorta: long term results. Int Angiol. 35(2):129-39.

21. Cho JW, Kwon OC, Lee S, Jang JS (2012) Traumatic aortic injury: singlecenter comparison of open versus endovascular repair. Korean J Thorac Cardiovasc Surg. 45(6):390-95.

22. Amabile P, Collart F, Gariboldi V, Rollet G, Bartoli JM, Piquet P (2004) Surgical versus endovascular treatment of traumatic thoracic aortic rupture. J Vasc Surg. 20(6):720-30.

23. McPhee JT et al (2007) The midterm results of stent graft treatment of thoracic aortic injuries. J Surg Res. .138(2):181-88.

\section{Publisher's Note}

Springer Nature remains neutral with regard to jurisdictional claims in published maps and institutional affiliations.

\section{Submit your manuscript to a SpringerOpen ${ }^{\circ}$ journal and benefit from:}

- Convenient online submission

- Rigorous peer review

- Open access: articles freely available online

- High visibility within the field

- Retaining the copyright to your article

Submit your next manuscript at $\boldsymbol{\nabla}$ springeropen.com 